\title{
Distribution and Impact of the Visceral Fat Area in Patients With Colorectal Cancer
}

\author{
Hyeon Yu, Yong-Geul Joh, Gyung-Mo Son ${ }^{2}$, Hyun-Sung Kim², Hong-Jae Jo², Hae-Young Kim² \\ Department of Surgery, Inje University Haeundae Paik Hospital, Inje University College of Medicine, Busan; ${ }^{1}$ Department of Surgery, Hansol \\ Hospital, Seoul; ${ }^{2}$ Department of Surgery, Pusan National University School of Medicine, Busan, Korea
}

Purpose: The purposes of this study were to investigate the distribution of the visceral fat area (VFA) and general obesity and to compare visceral and general obesity as predictors of surgical outcomes of a colorectal cancer resection.

Methods: The prospectively collected data of 102 patients with preoperatively-diagnosed sigmoid colon or rectal cancer who had undergone a curative resection at Pusan National University Yangsan Hospital between April 2011 and September 2012 were reviewed retrospectively. Men with a VFA of $>130 \mathrm{~cm}^{2}$ and women with a VFA of $>90 \mathrm{~cm}^{2}$ were classified as obese (VFA-O, $n=22$ ), and the remaining patients were classified as nonobese (VFA-NO, $n=80$ ).

Results: No differences in morbidity, mortality, postoperative bowel recovery, and readmission rate after surgery were observed between the 2 groups. However, a significantly higher number of harvested lymph nodes was observed in the VFANO group compared with the VFA-O group (19.0 \pm 1.0 vs. $13.5 \pm 1.2$, respectively, $\mathrm{P}=0.001)$.

Conclusion: Visceral obesity has no influence on intraoperative difficulties, postoperative complications, and postoperative recovery in patients with sigmoid colon or rectal cancer.

\section{Keywords: Colorectal neoplasms; Intra-abdominal fat; Surgical outcomes; Complications; Colon surgery}

\section{INTRODUCTION}

In the United States of America, the prevalence of obesity is 35.5\% among adult men and $35.8 \%$ among adult women, and there are approximately 1 billion overweight people worldwide [1]. According to a recent report, obesity and visceral obesity are closely related to the development of colorectal cancer, as well as other metabolic complications [2]. In addition, a previous article showed that obese patients had unfavorable surgical outcomes, including longer operative time, increased postoperative compli-

Received: September 10, 2015 - Accepted: November 13, 2015

Correspondence to: Yong-Geul Joh, M.D.

Department of Surgery, Hansol Hospital, 445 Songpa-daero, Songpa-gu,

Seoul 05616, Korea

Tel: +82-2-413-6363, Fax: +82-2-413-8186

E-mail: brosisjoh@naver.com

The oral presentation at the Young Investigator Award of the Korean Surgical Society, Seoul, Korea, December 1, 2012.

(c) 2016 The Korean Society of Coloproctology

This is an open-access article distributed under the terms of the Creative Commons Attribution NonCommercial License (http://creativecommons.org/licenses/by-nc/4.0) which permits unrestricted noncommercial use, distribution, and reproduction in any medium, provided the original work is properly cited. cation rate, increased conversion rate, and prolonged hospital stay [3]. However, body mass index (BMI) has been widely used to express the degree of obesity, although it does not always adequately reflect the degree of visceral fat [4]. Thus, we used the visceral fat area (VFA) to reflect the abdominal obesity directly and wanted to compare our result with the distribution of the populationbased fat area. The purpose of this study was to investigate the distribution of VFA and general obesity and to compare visceral and general obesity as predictors of surgical outcomes of a colorectal cancer resection.

\section{METHODS}

\section{Patients}

The prospectively collected data on patients with preoperativelydiagnosed sigmoid colon or rectal cancer who had undergone a curative resection at our hospital between April 2011 and September 2012 were reviewed retrospectively; 197 patients with unchecked metabolic profile or waist circumference were excluded, and 102 patients were enrolled in this study. The clinical parameters analyzed included the patients' characteristics, perioperative outcomes (operative times, estimated blood loss, numbers of 
Volume 32, Number 1, 2016

lymph nodes harvested, conversion rate, and intraoperative complications), and postoperative outcomes (days to flatus, stool, and food [liquid diet] intake, postoperative length of hospital stay, postoperative complications, readmission, and reoperation). Patients were staged using the TNM 7th edition. Operative time was calculated as the time between the first incision and wound closure. Before surgery, all patients underwent a standard bowel preparation 24 hours before the surgery and received oral antibiotics consisting of metronidazole. Prophylactic intravenous antibiotics were administered at the time of anesthetic induction and discontinued within 24 hours. Water could be taken orally on the day of surgery. Feeding began if the patient did not have an ileus and started with a liquid diet, progressing to a soft diet on the following day.

\section{Surgical procedure}

Surgery was performed by a surgical team consisting of 2 colorectal surgeons. Pneumoperitoneum was maintained at 10-12 $\mathrm{mmHg}$. Dissection was performed using a medial-to-lateral approach, and the mesenteric artery was divided at the level of the root of the inferior mesenteric artery or distal to the origin of the left colic artery, according to the extent of disease. The splenic flexure was taken down if necessary in order to achieve an adequate resection margin and to perform a tension-free anastomosis. An end-to-end anastomosis was performed using a doublestapling technique with a circular stapler; however, the transanal hand-sewn technique was used during a laparoscopic transabdominal transanal proctosigmoidectomy. The integrity of the anastomosis was verified by using an air-leak test, followed by placement of a pelvic drain in the vicinity of the anastomosis through the left lateral port site. All patients were scheduled for follow-up at seven days after discharge.

\section{Quantification of the area of visceral fat}

In the current study, all patients underwent an abdominal com- puted tomography (CT) scan for preoperative assessment of the extent of the disease. The CT scanner is linked to a networked medical imaging system through which images are transferred electronically to a centralized data system and then retrieved at a workstation (Rapidia 2.8 software, INFINITT Co., Seoul, Korea). Software enables rendering of multiple images and geometric measurements of a specific region with a specified CT number (in Hounsfield units) (Fig. 1). A single cross-sectional scan at the level of the umbilicus was selected for quantification $[4,5]$. Adipose tissue was determined by setting the attenuation level within the range of -190 to -30 Hounsfield units, and the acquired image corresponded to the total fat region $[6,7]$. Finally, the VFA was calculated by using the software. All quantifying procedures described above were performed by a single examiner, who was blinded to the surgical outcome at the time of quantification.

\section{Definition of obesity}

Several methods have been proposed for estimating the visceral obesity $[4,8,9]$. In this study, we divided patients into 2 groups according to the cutoff levels of VFA recommended by Oka et al. [10]. These levels take into account both sex-related differences and the quantity of visceral fat in Japanese. Men with a VFA $\geq 130$ $\mathrm{cm}^{2}$ and women with a VFA $\geq 90 \mathrm{~cm}^{2}$ were classified as obese (VFA-O), and the remaining patients were classified as nonobese (VFA-NO). BMI was calculated, and obese patients were defined as those with $\mathrm{BMI} \geq 25 \mathrm{~kg} / \mathrm{m}^{2}$ (BMI-O), and the remaining patients as nonobese (BMI-NO), in accordance with the Asia-Pacific Perspective: Redefining Obesity and its treatment proposed area-specific cut points [8]. Each patient in this study underwent preoperative screening for metabolic syndrome (MS). Diagnosis of MS was based on the 2005 American Heart Association and the National Heart, Lung, and Blood Institute criteria, which included the presence of three or more of the following parameters: waist circumference, blood pressure, triglyceride level, high-den-
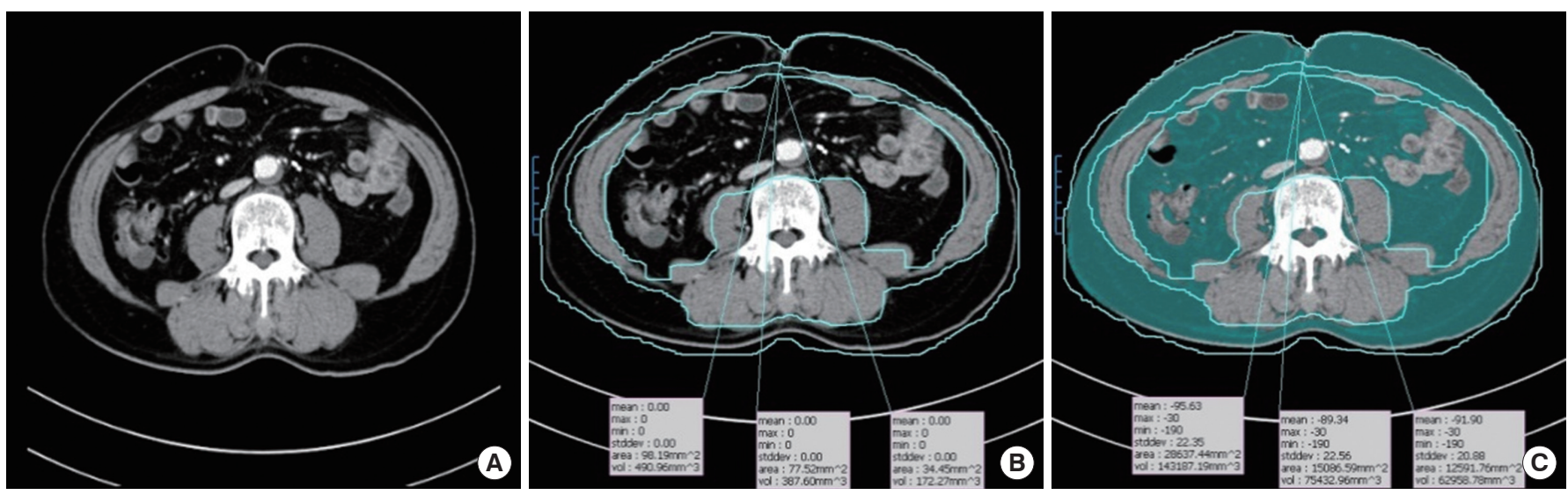

Fig. 1. Quantification of the visceral fat area on the computed tomography (CT) scan. (A) Original CT scan image at the level of the umbilicus. (B) The visceral fat region is determined by outlining the intra-abdominal component and the subcutaneous fat region. (C) Alteration of the window width for detection of adipose tissue. 
Table 1. AHA/NHBLI criteria for a clinical diagnosis of metabolic syndrome

\begin{tabular}{ll}
\hline Clinical measure & \multicolumn{1}{c}{ Categorical cut points } \\
\hline Elevated WC & $>40$ inches in males \\
& $>35$ inches in females \\
Elevated BP & $>130 \mathrm{mmHg}$ systolic BP or $>85 \mathrm{mmHg}$ diastolic BP \\
& $\begin{array}{c}\text { Receiving antihypertensive drug treatment in a } \\
\text { patient with a history of hypertension }\end{array}$ \\
& $>150 \mathrm{mg} / \mathrm{dL}$ \\
Elevated TG & Receiving drug treatment for elevated TG \\
& $<40 \mathrm{mg} / \mathrm{dL}$ in males \\
Reduced HDL-C & $<50 \mathrm{mg} / \mathrm{dL}$ in females \\
& Receiving drug treatment for reduced $\mathrm{HDL}-\mathrm{C}$ \\
Elevated fasting glucose & $>100 \mathrm{mg} / \mathrm{dL}$ \\
& Receiving drug treatment for elevated glucose \\
\hline
\end{tabular}

$\overline{\text { AHA/NHBLI, American Heart Association and the National Heart, Lung, and Blood }}$ Institute; WC, waist circumference; BP, blood pressure; TG, triglycerides; HDL-C, high-density lipoprotein cholesterol.

sity lipoprotein cholesterol level, and blood glucose level (Table 1) [11]. As there are no standard values for the definition of normal VFA/SFA ratio, we divided patients according to the percentiles of their VFA/SFA ratio [12].

\section{Statistical analysis}

Statistical analysis was performed using SPSS ver. 12.0 (SPSS Inc., Chicago, IL, USA). Numeral variables are expressed as mean \pm standard deviations or mean (range) and were compared using the Mann-Whitney U-test or the Student t-test. Categorical data were tabulated as percentages and compared using the Pearson chi-square test or Fisher exact probability test. Correlations between VFA and other obesity indices (BMI, MS, WC, and VFA/ SFA ratio) were examined using a one-way analysis of variance, and Pearson product-moment coefficient ( $\mathrm{r}$ ) was used to assess the correlations between obesity indices. Finally, the VFA and other obesity indices were examined for association with intraoperative and postoperative complications, reoperation, and readmission by using a multivariate model of logistic regression. A Pvalue of less than 0.05 was considered statistically significant.

\section{RESULTS}

\section{Characteristics of patients relative to visceral obesity}

This study included 102 patients with sigmoid colon or rectal cancer with an average age of 62 years (range, 32-85 years), of whom $65 \%$ were male. There were 22 VFA-O patients $(21.6 \%)$ and 80 VFA-NO patients (78.4\%). Fifty-four patients (18.1\%, 54 of 299) had MS. The demographic and the clinical characteristics of the 102 patients are shown in Table 2. Between the 2 groups, VFA-NO and VFA-O, no significant differences in age, American
Table 2. Clinicopathologic characteristics of the patients

\begin{tabular}{lccc}
\hline Variable & VFA-NO $(\mathrm{n}=80)$ & VFA-0 $(\mathrm{n}=22)$ & P-value \\
\hline Age (yr) & $60.8 \pm 1.1$ & $65.1 \pm 2.7$ & $\mathrm{NS}^{\mathrm{a}}$ \\
Gender & $56(70.0)$ & $10(45.5)$ & $0.03^{\mathrm{b}}$ \\
Male & $24(30.0)$ & $12(54.5)$ & \\
Female & & & \\
ASA grade & $39(48.8)$ & $7(31.8)$ & $\mathrm{NS}^{\mathrm{b}}$ \\
I & $31(38.8)$ & $11(50.0)$ & \\
II & $10(12.5)$ & $4(18.2)$ & \\
III & $17.9 \pm 6.8$ & $14.3 \pm 4.6$ & $\mathrm{NS}^{\mathrm{a}}$ \\
CEA (ng/mL) & & & \\
Operation & $37(46.3)$ & $12(54.5)$ & $\mathrm{NS}^{\mathrm{b}}$ \\
AR & $40(50.0)$ & $10(45.5)$ & \\
LAR & $3(3.8)$ & $0(0)$ & \\
LATA & & $4(18.2)$ & $\mathrm{NS}^{\mathrm{b}}$ \\
Stage & $31(38.8)$ & $18(81.8)$ & \\
O-I & $49(61.2)$ & & \\
II-III & &
\end{tabular}

Differentiation

$\begin{array}{lccc}\text { Well } & 17(21.3) & 5(22.7) & \text { NS }^{\mathrm{b}} \\ \text { Moderately } & 61(76.3) & 16(72.7) \\ \text { Poorly } & 0(0) & 0(0) \\ \text { Mucinous } & 1(1.2) & 1(4.5) \\ \text { Signet-ring } & 1(1.2) & 0(0)\end{array}$

Lymphatic invasion

$\begin{array}{lrrr}\text { Negative } & 72(90.0) & 19(86.4) & N^{b}\end{array}$

$8(10.0) \quad 3(13.6)$

Venous invasion

$\begin{array}{lccc}\text { Negative } & 74(92.5) & 22(100) & N^{\mathrm{b}} \\ \text { Positive } & 6(7.5) & 0(0) & \end{array}$

Perineural invasion

\begin{tabular}{lrrc}
\multicolumn{1}{l}{ Negative } & $63(78.8)$ & $17(77.3)$ & $\mathrm{NS}^{\mathrm{b}}$ \\
\multicolumn{1}{c}{ Positive } & $17(21.2)$ & $5(22.7)$ & \\
Retrieved lymph nodes & $19.0 \pm 1.0$ & $13.5 \pm 1.2$ & $0.001^{\mathrm{a}}$ \\
Tumor size (cm) & $3.7 \pm 0.2$ & $3.5 \pm 0.4$ & $\mathrm{NS}^{\mathrm{a}}$ \\
PRM (cm) & $10.7 \pm 0.7$ & $9.1 \pm 0.8$ & $\mathrm{NS}^{\mathrm{a}}$ \\
DRM (cm) & $5.6 \pm 0.4$ & $5.5 \pm 0.5$ & $\mathrm{NS}^{\mathrm{a}}$ \\
\hline
\end{tabular}

Values are presented as mean \pm standard deviations or number (\%). Men with a VFA of $>130 \mathrm{~cm}^{2}$ and women with a VFA of $>90 \mathrm{~cm}^{2}$ were classified as obese (VFA-0), and the remaining patients were classified as nonobese (VFA-NO).

VFA, visceral fat area; NS, not significant; ASA, American Society of Anesthesiologists; CEA, carcinoembryonic antigen; AR, anterior resection; LAR, low anterior resection; LATA, laparoscopic transabdominal transanal proctosigmoidectomy; PRM, proximal resection margin; DRM, distal resection margin.

aP-value is calculated from the Mann-Whitney U-test or the Student t-test. ${ }^{\text {bP- }}$ value is calculated from Pearson chi-square test or Fisher exact probability test. 
Society of Anesthesiologists score, preoperative carcinoembryonic antigen levels, or operative procedure were noted. VFA-O patients were more likely to be female than VFA-NO patients were. The pathologic data on the patients with or without visceral fat obesity are shown in Table 2. A specific difference in the numbers of retrieved nodes between the VFA-NO and VFA-O groups $(19 \pm 1.0$ vs. $13.5 \pm 1.2, \mathrm{P}=0.001)$ was noted.

\section{Distribution of visceral obesity and the relationship between the area of visceral fat and other obesity indices}

In order to examine the relationship between general obesity and the VFA in our sample, we tested the correlations between the VFA and different obesity indices (Table 3 ). We found a high correlation of the VFA with BMI $(\mathrm{r}=0.614, \mathrm{P}<0.001)$ (Fig. 2), WC $(\mathrm{r}$ $=0.636, \mathrm{P}<0.001)$, VFA/SFA ratio $(\mathrm{r}=0.340, \mathrm{P}=0.001)$, SFA $(\mathrm{r}=$ $0.569, \mathrm{P}<0.001)$, and TFA $(\mathrm{r}=0.811, \mathrm{P}<0.001)$. To examine the distribution of visceral obesity, we tested the comparison of obesity indices according to age. As people grow older, the VFA increases; however, the SFA decreases. The VFA/SFA ratio showed a statistically significant difference with age (Table 4).

\section{Surgical outcomes of patients relative to visceral obesity}

Intraoperative variables used for assessing the technical difficulty are shown in Table 5. The intraoperative morbidity was $5.0 \%$ in the VFA-NO group and $4.5 \%$ in the VFA-O group. The difference did not reach statistical significance. The conversion rate was $2.5 \%$ in the VFA-NO group, and the reasons were intractable adhesions

Table 3. Coefficients for correlations of the area of visceral fat with other obesity indices

\begin{tabular}{lcc}
\hline Variable & Coefficients $(r)$ & P-value \\
\hline Body mass index & 0.641 & $<0.001$ \\
Waist circumference & 0.636 & $<0.001$ \\
VFA/SFA ratio & 0.340 & 0.001 \\
SFA & 0.569 & $<0.001$ \\
TFA & 0.811 & $<0.001$ \\
\hline
\end{tabular}

VFA, visceral fat area; SFA, subcutaneous fat area; TFA, total fat area. in the context of obesity and a bulky tumor.

The postoperative outcomes used for assessing the short-term outcomes are shown in Table 5. The postoperative morbidity was $42.5 \%$ in the VFA-NO group and $31.8 \%$ in the VFA-O group, including drain infection in 1 patient, dermatitis in 2 , chylous ascites in 3 , delirium in 1 , pancreatitis in 2 , leg numbness due to epidural block in 1 , and dizziness in 1 . There was no mortality in this study. No significant difference in time to recovery of postoperative gastrointestinal function was observed between the VFA-NO and the VFA-O groups. There were 5 readmissions. In 2 cases, voiding difficulty and dizziness were managed nonoperatively. One patient experienced gastritis and another patient had a wound infection. In 1 patient, anastomotic insufficiency was managed in the operating room by aseptic irrigation and drainage because he had undergone a diverting ileostomy. Two patients underwent a reoperation for anastomotic leakage on postopera-

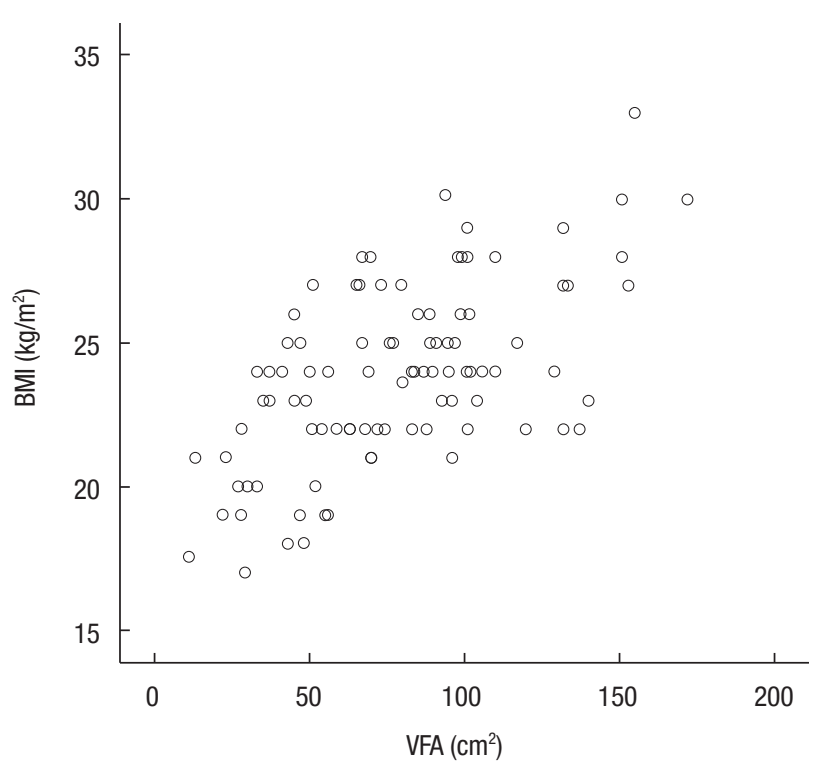

Fig. 2. Scatter plots showing the correlation between the visceral fat area (VFA) and the body mass index (BMI).

Table 4. Obesity indices according to age

\begin{tabular}{|c|c|c|c|c|c|c|}
\hline \multirow{2}{*}{ Variable } & \multicolumn{5}{|c|}{ Age group (yr) } & \multirow{2}{*}{ P-value } \\
\hline & $<50(\mathrm{n}=12)$ & $51-60(n=28)$ & $61-70(n=38)$ & $71-80(n=20)$ & $>80(n=4)$ & \\
\hline BMI $\left(\mathrm{kg} / \mathrm{m}^{2}\right)$ & $24.1 \pm 1.1$ & $23.8 \pm 0.5$ & $23.8 \pm 0.6$ & $23.7 \pm 0.6$ & $24.3 \pm 2.0$ & NS \\
\hline WC (cm) & $84.4 \pm 3.1$ & $85.4 \pm 1.4$ & $86.6 \pm 1.6$ & $85.4 \pm 1.5$ & $89.9 \pm 4.6$ & NS \\
\hline VFA $\left(\mathrm{cm}^{2}\right)$ & $71.2 \pm 13.3$ & $72.4 \pm 6.5$ & $78.0 \pm 5.2$ & $90.1 \pm 8.3$ & $86.8 \pm 19.9$ & NS \\
\hline SFA $\left(\mathrm{cm}^{2}\right)$ & $142.5 \pm 25.0$ & $143.4 \pm 9.6$ & $140.6 \pm 11.3$ & $132.5 \pm 11.8$ & $143.0 \pm 17.7$ & NS \\
\hline VFA/SFA ratio & $52.1 \pm 6.4$ & $53.0 \pm 4.8$ & $61.2 \pm 4.2$ & $77.0 \pm 7.2$ & $61.5 \pm 14.3$ & 0.03 \\
\hline
\end{tabular}

Values are presented as mean \pm standard deviation.

BMI, body mass index; MS, metabolic syndrome; WC, waist circumference; VFA/SFA ratio, visceral fat area/subcutaneous fat area; NS, not significant.

P-value is calculated from the one-way analysis of variance. 
Table 5. Surgical outcomes

\begin{tabular}{|c|c|c|c|}
\hline Variable & VFA-NO $(n=80)$ & VFA-0 $(n=22)$ & P-value \\
\hline Operation time (min) & $181.7 \pm 7.7$ & $169.8 \pm 12.8$ & $N S^{a}$ \\
\hline $\mathrm{EBL}(\mathrm{mL})$ & $81.1 \pm 12.7$ & $109.8 \pm 44.4$ & $N S^{a}$ \\
\hline \multicolumn{4}{|l|}{ IntraOP CX. } \\
\hline No & $76(95.0)$ & $21(95.5)$ & $N S^{b}$ \\
\hline Bleeding & $1(1.3)$ & $1(4.5)$ & \\
\hline Anastomotic insufficiency & $3(3.8)$ & $0(0)$ & \\
\hline Conversion & $2(2.5)$ & $0(0)$ & $N S^{b}$ \\
\hline Flatus (day) & $2.3 \pm 0.1$ & $2.3 \pm 0.2$ & $N S^{a}$ \\
\hline Defecation (day) & $3.7 \pm 0.2$ & $3.9 \pm 0.4$ & $N S^{a}$ \\
\hline Diet (day) & $2.7 \pm 0.1$ & $2.8 \pm 0.3$ & $N S^{a}$ \\
\hline Hospital stay (day) & $7.8 \pm 0.6$ & $7.5 \pm 0.8$ & $N S^{a}$ \\
\hline \multicolumn{4}{|l|}{ PostOP CX. } \\
\hline No & $46(57.5)$ & $15(68.2)$ & $N S^{b}$ \\
\hline Pulmonary & $1(1.3)$ & $0(0)$ & \\
\hline Leakage & $3(3.8)$ & $1(4.5)$ & \\
\hline lleus & $7(8.8)$ & $3(13.6)$ & \\
\hline Wound infection & $2(2.5)$ & $0(0)$ & \\
\hline Urinary & $12(15.0)$ & $1(4.5)$ & \\
\hline Others & $9(11.3)$ & $2(9.1)$ & \\
\hline \multicolumn{4}{|l|}{ Reoperation } \\
\hline No & 77 (96.3) & 21 (95.5) & $N S^{b}$ \\
\hline Yes & $3(3.8)$ & $1(4.5)$ & \\
\hline \multicolumn{4}{|l|}{ Readmission } \\
\hline No & 75 (93.8) & $22(100)$ & $\mathrm{NS}^{b}$ \\
\hline Yes & $5(6.3)$ & $0(0)$ & \\
\hline
\end{tabular}

Values are presented as mean \pm standard deviations or number (\%). Men with a VFA of $>130 \mathrm{~cm}^{2}$ and women with a VFA of $>90 \mathrm{~cm}^{2}$ were classified as obese (VFA-0), and the remaining patients were classified as nonobese (VFA-NO).

VFA, visceral fat area; EBL, estimated blood loss; IntraOP CX., intraoperative complication; PostOP CX., postoperative complication; NS, not significant.

aP-value is calculated from the Mann-Whitney U-test or the Student t-test. ${ }^{b} \mathrm{P}$ value is calculated from Pearson chi-square test or Fisher exact probability test. tive days 4 and 27, respectively. An anastomotic hemorrhage was resolved with surgical suture ligation in 1 patient.

\section{Correlation of obesity with operative outcomes (Table 6)}

A multivariate analysis was performed in order to estimate the correlation of obesity with operative outcomes (intraoperative complication, postoperative complication, readmission, and reoperation). The risk for intraoperative complications was not significant; neither were the risks associated with BMI, WC, VFA, and VFA/SFA ratio. However, MS was on obvious risk for postoperative complications ( $\mathrm{P}=0.017$; odds ratio, 2.987). In the multivariate analysis, the risks for readmission and reoperation did not reach statistical significance.

\section{DISCUSSION}

In this study, we investigated the surgical outcomes for viscerally obese patients with colorectal cancer. No significant differences in outcomes were observed between the obese and the nonobese patients. Obesity, a growing health problem worldwide, is usually defined using the BMI. In particular, increasing BMI has been associated with colorectal carcinogenesis $[13,14]$. Besides general obesity, which is expressed by the BMI, the distribution of adipose tissue also seems to be important in the pathogenesis of colorectal cancer [15]. Increased visceral obesity, measured by using the VFA and the VFA/SFA ratio, has been examined as a predictor of colorectal surgery outcome $[4,12,16]$. In those studies, visceral obesity was associated with prolonged operative time [16], increased postoperative complications $[2,16]$, shorter disease-free survival [12], and longer hospital stay [2] after a resection for colorectal cancer.

Although the BMI has been considered one of the most reliable anthropometric indices of obesity, several techniques have recently been developed for assessing the VFA from a single CT scan obtained at the level of the umbilicus. The VFA has been shown to correlate closely with the total volume of visceral fat [6, 17]. In addition, accumulating evidence has suggested a strong association between visceral obesity and MS, as discussed in recent reviews [18, 19]. Lohsiriwat et al. [2] reported a higher rate of

Table 6. Risk factors for intraoperative complication, postoperative complication, reoperation, and readmission based on the multivariate analysis

\begin{tabular}{|c|c|c|c|c|c|c|c|c|}
\hline \multirow{2}{*}{ Variable } & \multicolumn{2}{|c|}{ Intraoperative complication } & \multicolumn{2}{|c|}{ Postoperative complication } & \multicolumn{2}{|c|}{ Reoperation } & \multicolumn{2}{|c|}{ Readmission } \\
\hline & P-value & $\mathrm{OR}$ & P-value & $\mathrm{OR}$ & P-value & $\mathrm{OR}$ & P-value & $\mathrm{OR}$ \\
\hline $\mathrm{BMl}$ & NS & 3.276 & NS & 1.328 & NS & 7.816 & NS & 0.651 \\
\hline MS & NS & 0.317 & 0.017 & 2.987 & NS & 3.061 & NS & 2.347 \\
\hline WC & NS & 5.008 & NS & 0.395 & NS & 0.000 & NS & 0.000 \\
\hline VFA & NS & 0.388 & NS & 0.458 & NS & 2.157 & NS & 0.000 \\
\hline VFA/SFA ratio & NS & 4.922 & NS & 1.650 & NS & 0.277 & NS & 0.426 \\
\hline
\end{tabular}

OR, odds ratio; BMI, body mass index; NS, not significant; MS, metabolic syndrome; WC, waist circumference; VFA, visceral fat area; SFA, subcutaneous fat area. 
postoperative complications and a longer length of hospital stay in patients with MS than in patients without MS.

In our study, visceral obesity had no influence on intraoperative difficulties, postoperative complications, and postoperative recovery in patients with colorectal cancer, but did have an influence on the number of harvested lymph nodes. The number of harvested lymph nodes, with resection margin status, is a measure of the oncologic adequacy of the resection. In addition to a low average lymph node yield of 9.5, Ballian et al. [20] found an association of increasing visceral obesity with reduced retrieval of lymph nodes. Moon et al. [12] suggested a lack of association between the VFA/SFA ratio and the number of lymph nodes harvested in 161 patients undergoing a laparoscopic resection for colorectal cancer. However, in that study, only $59 \%$ of patients had rectal cancer, and the VFA/SFA ratio was measured at the level of the iliac crests and umbilicus. In their study of 141 proctectomy specimens, Gorog et al. [21] found that specimens from patients with BMI $>25 \mathrm{~kg} / \mathrm{m}^{2}$ and measuring $<16 \mathrm{~cm}$ in length contained significantly fewer lymph nodes than those from patients with BMI $<25 \mathrm{~kg} / \mathrm{m}^{2}$. No significant differences in lymph node retrieval were observed in patients with specimens longer than $16 \mathrm{~cm}$, nor did obese patients tend to have shorter proctectomy specimens. A significant difference in the number of harvested lymph nodes was observed between our two groups, the VFA-NO and the VFA-O groups. We speculate that these results were due to the variable cutoff value of the VFA; i.e., men with a VFA of $\geq 130 \mathrm{~cm}^{2}$ and women with a VFA of $\geq 90 \mathrm{~cm}^{2}$ were classified as obese. Although we divided patients into two groups according to the cutoff levels of the VFA recommended by Oka et al. [10], different criteria for different genders might induce differences in the surgical outcomes for patients with colorectal cancer. A second explanation for the similar operative outcomes is the observation that the rectal cancer tumors were larger in VFA-NO than in VFA-O, but the tumor locations were not statistically different.

As to the relationship between the VFA and other obesity indices, the current study showed high correlations of the VFA with the BMI, WC, and VFA/SFA ratio. However, if simplicity and opportunity costs are considered in the preoperative evaluation of patients' obesity, the method measuring the BMI and the WC might be a better way to assess obesity. On the distribution of visceral fat according to age, visceral obesity increased with age, but the SFA decreased. As a result, the VFA/SFA ratio increased until patients were in their 70s and decreased in patients aged 80 years and older. In addition, the VFA/SFA ratio showed statistical significance according to age. Furthermore, as described in other studies $[20,22]$, we may suppose that the BMI, the VFA/body surface area and the VFA/SFA ratio are more reliable as predictive factors of short-term surgical outcomes for patients with sigmoid colon or rectal cancer.

Ballian et al. [20] reported an association of visceral obesity with postoperative, oncologic, and survival outcomes of a TME for a rectal adenocarcinoma. There were no significant risks for intra- operative and postoperative complications, reoperation, or readmission, except for patient with MS (OR, 2.987; P = 0.017). In the current study, we postulated that visceral obesity would not affect the results of surgery because the mean BMI of our samples was $23.9 \pm 0.33 \mathrm{~kg} / \mathrm{m}^{2}$ and the number of morbidly obese patients was lower than that of Western people.

This study had several limitations. First, it was retrospective in design, although the data were collected prospectively. Second, our samples were small, and patients underwent various operative procedures, which increases the heterogeneity. Because the cutoff value of visceral obesity in women was lower, many more women were included in the VFA-O group.

In conclusion, we found a high correlation of VFA with waist circumference and the VFA/SFA ratio. As people grow older, the VFA increases, but the SFA decreases. In this study, we found that visceral obesity had no influence on intraoperative difficulties, postoperative complications, and postoperative recovery in patients with colorectal cancer.

\section{CONFLICT OF INTEREST}

No potential conflict of interest relevant to this article was reported.

\section{REFERENCES}

1. Flegal KM, Carroll MD, Kit BK, Ogden CL. Prevalence of obesity and trends in the distribution of body mass index among US adults, 1999-2010. JAMA 2012;307:491-7.

2. Lohsiriwat V, Pongsanguansuk W, Lertakyamanee N, Lohsiriwat D. Impact of metabolic syndrome on the short-term outcomes of colorectal cancer surgery. Dis Colon Rectum 2010;53:186-91.

3. Pikarsky AJ, Saida Y, Yamaguchi T, Martinez S, Chen W, Weiss EG, et al. Is obesity a high-risk factor for laparoscopic colorectal surgery? Surg Endosc 2002;16:855-8.

4. Tsujinaka S, Konishi F, Kawamura YJ, Saito M, Tajima N, Tanaka O, et al. Visceral obesity predicts surgical outcomes after laparoscopic colectomy for sigmoid colon cancer. Dis Colon Rectum 2008; 51:1757-65.

5. Yoshizumi T, Nakamura T, Yamane M, Islam AH, Menju M, Yamasaki K, et al. Abdominal fat: standardized technique for measurement at CT. Radiology 1999;211:283-6.

6. Kvist H, Chowdhury B, Sjostrom L, Tylen U, Cederblad A. Adipose tissue volume determination in males by computed tomography and 40K. Int J Obes 1988;12:249-66.

7. Park HS, Lee K. Greater beneficial effects of visceral fat reduction compared with subcutaneous fat reduction on parameters of the metabolic syndrome: a study of weight reduction programmes in subjects with visceral and subcutaneous obesity. Diabet Med 2005; 22:266-72.

8. International Diabetes Institute; World Health Organization; Regional Office for the Western Pacific; International Association 
for the Study of Obesity; International Obesity Task Force. The Asia Pacific perspective: redefining obesity and its treatment. Sydney: Health Communications Australia; 2000.

9. Kunisaki C, Makino H, Yamamoto N, Sato T, Oshima T, Nagano Y, et al. Learning curve for laparoscopy-assisted distal gastrectomy with regional lymph node dissection for early gastric cancer. Surg Laparosc Endosc Percutan Tech 2008;18:236-41.

10. Oka R, Kobayashi J, Yagi K, Tanii H, Miyamoto S, Asano A, et al. Reassessment of the cutoff values of waist circumference and visceral fat area for identifying Japanese subjects at risk for the metabolic syndrome. Diabetes Res Clin Pract 2008;79:474-81.

11. Grundy SM, Cleeman JI, Daniels SR, Donato KA, Eckel RH, Franklin BA, et al. Diagnosis and management of the metabolic syndrome: an American Heart Association/National Heart, Lung, and Blood Institute Scientific Statement. Circulation 2005;112: 2735-52.

12. Moon HG, Ju YT, Jeong CY, Jung EJ, Lee YJ, Hong SC, et al. Visceral obesity may affect oncologic outcome in patients with colorectal cancer. Ann Surg Oncol 2008;15:1918-22.

13. Martínez ME, Heddens D, Earnest DL, Bogert CL, Roe D, Einspahr J, et al. Physical activity, body mass index, and prostaglandin E2 levels in rectal mucosa. J Natl Cancer Inst 1999;91:950-3.

14. Renehan AG, Tyson M, Egger M, Heller RF, Zwahlen M. Bodymass index and incidence of cancer: a systematic review and metaanalysis of prospective observational studies. Lancet 2008;371:56978.
15. Wang Y, Jacobs EJ, Patel AV, Rodriguez C, McCullough ML, Thun MJ, et al. A prospective study of waist circumference and body mass index in relation to colorectal cancer incidence. Cancer Causes Control 2008;19:783-92.

16. Ishii $Y$, Hasegawa H, Nishibori H, Watanabe M, Kitajima M. Impact of visceral obesity on surgical outcome after laparoscopic surgery for rectal cancer. Br J Surg 2005;92:1261-2.

17. Tokunaga K, Matsuzawa Y, Ishikawa K, Tarui S. A novel technique for the determination of body fat by computed tomography. Int J Obes 1983;7:437-45.

18. Despres JP. Is visceral obesity the cause of the metabolic syndrome? Ann Med 2006;38:52-63.

19. Despres JP, Lemieux I. Abdominal obesity and metabolic syndrome. Nature 2006;444:881-7.

20. Ballian N, Lubner MG, Munoz A, Harms BA, Heise CP, Foley EF, et al. Visceral obesity is associated with outcomes of total mesorectal excision for rectal adenocarcinoma. J Surg Oncol 2012;105: 365-70.

21. Gorog D, Nagy P, Peter A, Perner F. Influence of obesity on lymph node recovery from rectal resection specimens. Pathol Oncol Res 2003;9:180-3.

22. Seki Y, Ohue M, Sekimoto M, Takiguchi S, Takemasa I, Ikeda M, et al. Evaluation of the technical difficulty performing laparoscopic resection of a rectosigmoid carcinoma: visceral fat reflects technical difficulty more accurately than body mass index. Surg Endosc 2007;21:929-34. 